2015-10-03

\title{
Action cameras: Bringing aquatic and fisheries research into view
}

Struthers, DP

http://hdl.handle.net/10026.1/11452

10.1080/03632415.2015.1082472

Fisheries

All content in PEARL is protected by copyright law. Author manuscripts are made available in accordance with publisher policies. Please cite only the published version using the details provided on the item record or document. In the absence of an open licence (e.g. Creative Commons), permissions for further reuse of content should be sought from the publisher or author. 
Fisheries

\section{Action Cameras: Bringing Aquatic and Fisheries Research into View}

\section{Daniel P. Struthers, Andy J. Danylchuk, Alexander D. M. Wilson \& Steven J. Cooke}

To cite this article: Daniel P. Struthers, Andy J. Danylchuk, Alexander D. M. Wilson \& Steven J. Cooke (2015) Action Cameras: Bringing Aquatic and Fisheries Research into View, Fisheries, 40:10, 502-512, DOI: 10.1080/03632415.2015.1082472

To link to this article: http://dx.doi.org/10.1080/03632415.2015.1082472

$$
\text { 曲 Published online: } 12 \text { Oct } 2015 .
$$

Submit your article to this journal $₫$

Q View related articles

View Crossmark data $\nearrow$ 

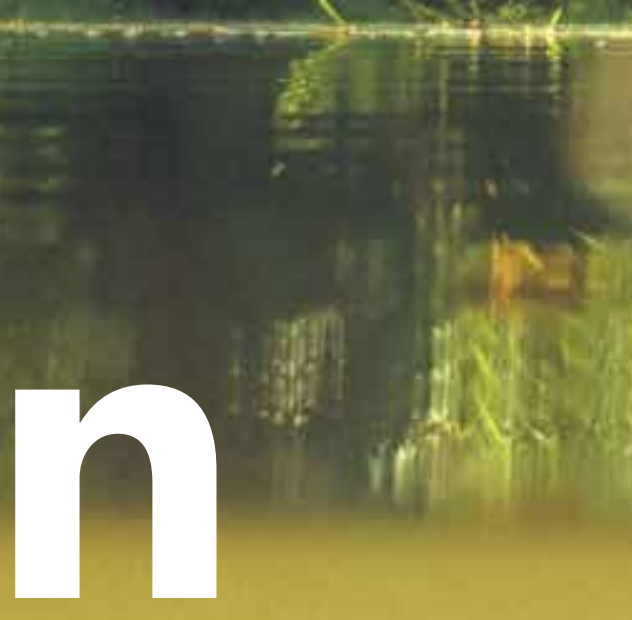

$\sqrt{10}$

\section{FEATURE}
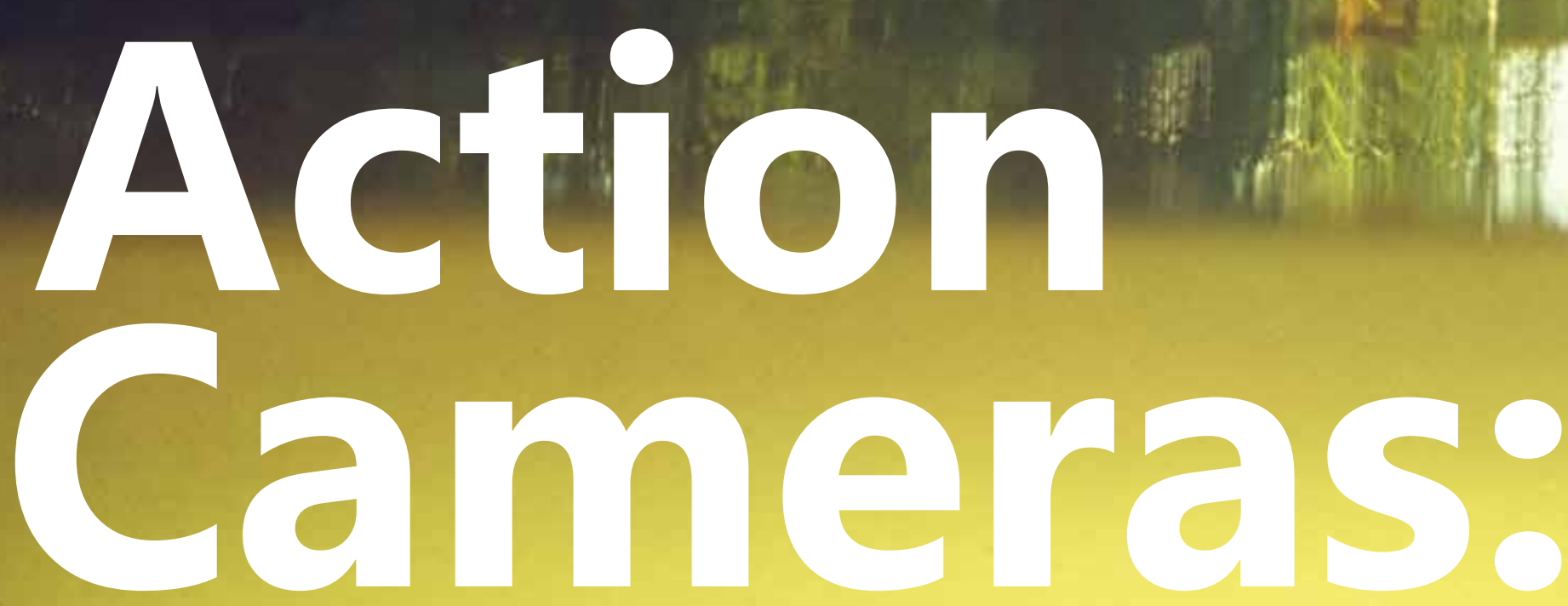

\section{Bringing Aquatic}

\section{and Fisheries}

\section{Res Research into View}

\section{Daniel P. Struthers}

Fish Ecology and Conservation Physiology Laboratory, Department of Biology, Carleton University, 1125 Colonel By Dr., Ottawa, ON K1S 5B6, Canada. E-mail: danielstruthers@cmail.carleton.ca

\section{Andy J. Danylchuk}

Department of Environmental Conservation, University of Massachusetts-Amherst, Amherst, MA

\section{Alexander D. M. Wilson}

Fish Ecology and Conservation Physiology Laboratory, Department of Biology, Carleton University, Ottawa, ON, Canada

\section{Steven J. Cooke}

Fish Ecology and Conservation Physiology Laboratory, Department of Biology, and Institute of Environmental Science, Carleton University, Ottawa, ON, Canada 

1) Dain

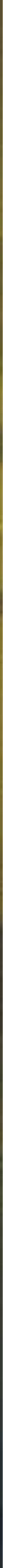


Digital action cameras (ACs) are increasingly being utilized for aquatic research purposes due to their cost effectiveness, versatility, high-resolution imagery, and durability. Here we review the advantages of AC technology in research, with particular emphases on (a) research videography (both in the field and the laboratory), (b) animal-borne studies, and (c) outreach and education purposes. We also review some of the limitations of this technology as represented by environmental factors (e.g., depth, turbidity) and deployment considerations (e.g., lens choices, imaging settings, battery life). As AC technologies evolve in response to growing public interest in their application versatility, researchers are indirectly reaping the rewards, with technological advances that are innovative, cost-effective, and can withstand frequent use in dynamic and rugged field conditions. With such a diversity of options available, future usefulness of ACs in research will only be limited by the creativity of the scientists using them.

\section{Cámara de acción: poniendo en escena la investigación acuática y pesquera}

Las cámaras digitales de acción (CA) están siendo cada vez más utilizadas con fines de investigación acuática debido a la efectividad en términos de costos, versatilidad, imágenes de alta resolución y durabilidad. Aquí se hace una revisión de las ventajas de la tecnología de las cámaras de acción en la investigación, con énfasis en (a) investigación videográfica (en campo y laboratorio), (b) estudios con animales y (c) propósitos de difusión y educación. También se revisan algunas de las limitaciones de esta tecnología en función de factores ambientales (p.e. profundidad y turbidez) y de consideraciones de uso (p.e. elección de lentes, opciones de imágenes, vida de las baterías). Dado que la tecnología de las CA evoluciona de acuerdo al interés del público en cuanto a la versatilidad de su aplicación, los investigadores están indirectamente cosechando los beneficios con avances tecnológicos que son innovadores, económicos y que pueden soportar el uso constante de las cámaras bajo las arduas condiciones del trabajo en campo. Con tal diversidad de opiniones disponibles, la utilidad de las cámaras de acción en el futuro, dentro del área de la investigación, sólo estará limitada por la creatividad de los investigadores que las usan.

\section{Caméscopes en action : Mettre les recherches aquatiques et halieutiques en point de mire}

Les caméscopes sportifs numériques (CSN) sont de plus en plus utilisés à des fins de recherche aquatique en raison de leur rapport coût-efficacité, de leur polyvalence, de leurs images haute résolution, et de leur durabilité. Ici, nous passons en revue les avantages de la technologie du caméscope sportif en matière de recherche, en mettant l'accent sur (a) la vidéographie de recherche (à la fois sur le terrain et en laboratoire), (b) les études animalières, et (c) la sensibilisation et l'éducation. Nous examinons aussi certaines des limites de cette technologie telles que représentées par des facteurs environnementaux (par exemple, la profondeur, la turbidité) et les considérations d'utilisation (par exemple, le choix de lentilles, les paramètres d'imagerie, la durée de vie de la batterie). Les technologies CSN évoluent en réponse à l'intérêt croissant du public pour leur polyvalence. Les chercheurs en récoltent indirectement les fruits. Les progrès technologiques sont novateurs, rentables, et l'appareil résiste à un usage fréquent dans des conditions dynamiques et difficiles sur le terrain. Avec une telle diversité d'options disponibles, l'utilité future des caméscopes sportifs en matière de recherche ne sera limitée que par la créativité des scientifiques qui les utilisent.

\section{INTRODUCTION}

Video cameras are an important tool for collecting data in remote locations where diving or other means of observationbased data collection would be dangerous or unfeasible for scientists (Collins et al. 1991). For fisheries research, videography began soon after the introduction of the first videotape recorder in 1951 (Bellis 2004). Shortly thereafter, scientists began applying underwater video cameras (albeit large) to the study of fish behavior, benthic organisms, and plankton (Barnes 1952; Brawn 1960; Richard 1968). Earlier uses were also applied to better understand animal interactions with commercial fishing gear (Livingstone 1962).

The first seafloor-mounted underwater camera units designed by Kumpf and Lowenstein (1962) and Stevenson and Myrberg (1966) were used to document species diversity/abundance and behavior (Steinberg et al. 1965; Myrberg et al. 1969). These camera systems were considered relatively small for their time (measuring $1 \mathrm{~m}$ in height and $0.5 \mathrm{~m}$ in diameter) and required a tether to a land-based power supply and video recorder. Though remarkably innovative and important for early aquatic research, these first underwater video units were impractical for widespread use in fisheries science applications due to their large size and high cost and the need for customized mounts and waterproof housings.

Consumer demand for enhanced video devices resulted in the development of affordable and commercially available video products for the general public. These cameras evolved quickly as manufacturers developed smaller units with enhanced picture qualities. During the 1990s and early 2000s, handheld digital video cameras (both battery powered and tethered) were commonly used in fisheries and aquatic research for assessing habitat (Carleton and Done 1995; Heithaus et al. 2002), estimating fish size (Harvey et al. 2002; Costa et al. 2006), characterizing community assemblage structure (Booth and Beretta 2002; Cooke and Schreer 2002), validating foraging models (Hughes et al. 2003), and documenting the behavior of wild fish (Hinch and Rand 2000; Heithaus et al. 2002; He 2003) and cultured fish (Foster et al. 1995; Ang and Petrell 1997; Michel et al. 2002). Camera technology also enabled research to be conducted in a variety of conditions that were previously unfeasible, such as under ice cover (Mueller et al. 2006) or in deep-sea environments (De Leo et al. 2010). Despite these advances, digital cameras still had constraints (i.e., short battery life, need for custom housings, and cumbersome size) and were challenging to use in high-energy (e.g., waves, river flows) environments.

More recently, advances with imaging technology and innovative mechanical systems for mounting cameras have given rise to the action camera (AC). These lightweight, compact, and wireless (archival) devices are easily secured to most surfaces and durable enough to withstand use in highenergy environments. Initially marketed for recording extreme sports (i.e., surfing, skydiving, skiing), the crossover research benefits of such ACs have attracted the attention of aquatic 
researchers. The objectives of this article are to (1) review the use of AC technology and identify key components that make them useful for aquatic research, (2) summarize the existing applications for $\mathrm{AC}$ units in fisheries research, and (3) identify the challenges and opportunities for deploying ACs in aquatic systems.

\section{OVERVIEW OF ACTION CAMERAS}

Revolutionizing Videography for Aquatic Research

Underwater video cameras are a cost-effective method for capturing important data regarding ecological interactions and fish behavior without the potentially disruptive presence of an observer (Collins et al. 1991; Beddow et al. 1996; Cooke and Bunt 2004). In 2004, the first AC - the GoPro HERO (San Mateo, CA, USA) - was introduced to the consumer marketplace. Since then, a variety of manufacturers have produced ACs (Figure 1), which continue to evolve as new technology becomes available. Here we briefly review the key components that make ACs ideal for many fisheries and aquatic research applications including cost, design, and picture quality.

\section{Cost}

Action cameras are produced by several manufacturers and provide consumers with a variety of relatively inexpensive (ranging from US\$99 for entry-level models to US\$399 for higher-quality models) options to choose from (Table 1). Due to their low risk-reward ratio, the advantages of ACs for research become obvious when compared to other more prohibitive, specialized camera options, which can range into the thousands (e.g., camera housings designed for SCUBA diving, ROV cameras, the Crittercam) or tens of thousands of dollars (e.g., underwater sonar camera units, which can cost $\sim$ US $\$ 80,000)$.

\section{Design}

Due to their intended use in active recreational sports, the majority of AC products are "shockproof," built to withstand drops from low-level heights or constant jarring. Similarly, many ACs possess integrated lithium-ion batteries and

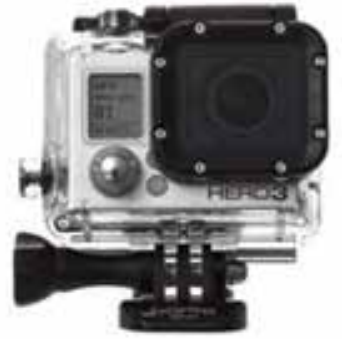

GOPRO HERO 3

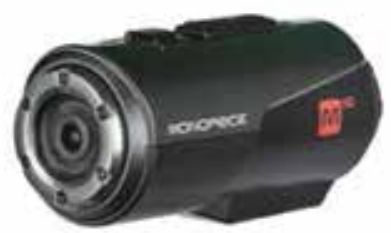

Monoprice MHD

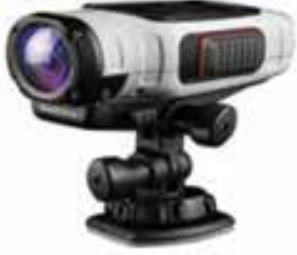

Garmin VIRB Elite

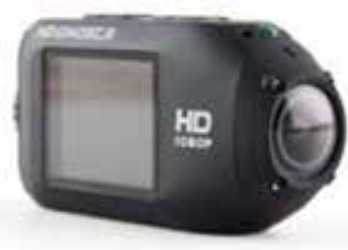

Drift Ghost HD
Figure 1. Examples of action cameras available on the market.

high-capacity memory cards, which allow them to function independently (albeit for a short term) in a manner similar to biologging devices (e.g., accelerometers, thermal loggers). As an added advantage for aquatic research, many ACs are equipped with waterproof housing systems capable of withstanding substantial pressure (Table 1). In some instances, manufacturers provide out-of-the-box waterproof devices without the need for additional housing systems, making ACs even smaller and lighter. There are also numerous specialized mounting packages for some ACs provided from camera manufacturers (e.g., harnesses, clips for sporting equipment, flexible arms and levers), which makes it easier to secure camera units to

Table 1. Important characteristics of popular action camera brands on the market (as of July 2014). Note that data provided emenate from manufacturer-provided specifications and were not independently verified for this article.

\begin{tabular}{|c|c|c|c|c|c|c|c|c|}
\hline $\begin{array}{l}\text { Action } \\
\text { Camera } \\
\text { Model } \\
\end{array}$ & $\begin{array}{l}\text { MSRP } \\
(\$)\end{array}$ & $\begin{array}{l}\text { Depth } \\
\text { Capacity }\end{array}$ & $\begin{array}{l}\text { Lens field- } \\
\text { of-view } \\
\text { (degrees) }\end{array}$ & $\begin{array}{l}\text { Unit size } \\
(\mathrm{mm})\end{array}$ & $\begin{array}{l}\text { Weight } \\
\text { (g) }\end{array}$ & $\begin{array}{l}\text { Estimated } \\
\text { Battery Life } \\
\text { (hr:min) }\end{array}$ & Resolution/FPS & $\begin{array}{l}\text { Megapixels } \\
\text { (MP); Burst- } \\
\text { Rate (FPS) }\end{array}$ \\
\hline $\begin{array}{l}\text { GoPro HD } \\
\text { Hero } 4\end{array}$ & $\begin{array}{l}\$ 199- \\
\$ 399\end{array}$ & $60 \mathrm{~m}$ & $170^{\circ}$ & $41 \times 59 \times 21$ & 83 & $2: 00$ & 720p; 960p; 1080p; 1440p/24-120 & $12 ; 30$ \\
\hline Garmin VIRB & $\begin{array}{l}\$ 299- \\
\$ 399\end{array}$ & $50 \mathrm{~m}$ & $150^{\circ}$ & $32 \times 53 \times 111$ & 178 & $3: 00$ & 720p; 960p; 1080p/30-60 & $16 ; 6$ \\
\hline Contour +2 & $\$ 399$ & $60 \mathrm{~m}$ & $170^{\circ}$ & $98 \times 60 \times 34$ & 156 & $2: 30$ & 720p; 960p; 1080p/30-60 & $5 ; 1-60$ \\
\hline $\begin{array}{l}\text { Drift Ghost } \\
\text { HD }\end{array}$ & $\$ 299$ & $60 \mathrm{~m}$ & $170^{\circ}$ & $\begin{array}{l}33 \times 51 \times \\
104\end{array}$ & 167 & $3: 30$ & 720p; 960p; 1080p/25 - 60 & $12 ; 10$ \\
\hline Ion Air Pro 3 & $\$ 349$ & $15 \mathrm{~m}$ & $160^{\circ}$ & $37 \times 107$ & 134 & $2: 30$ & 720p; 1080p/30 - 120 & $12 ; 10$ \\
\hline $\begin{array}{l}\text { Monoprice } \\
\text { MHD }\end{array}$ & $\$ 99$ & $60 \mathrm{~m}$ & $120^{\circ}$ & $28 \times 104$ & 110 & $3: 00$ & $720 p ; 1080 p / 30-60$ & $5 ; 10$ \\
\hline Muvi HD10 & $\$ 219$ & $60 m$ & $170^{\circ}$ & $80 \times 47 \times 19$ & 78 & $3: 00$ & 720p; 960p; 1080p/30 & 8; NA \\
\hline $\begin{array}{l}\text { JVC Adixx- } \\
\text { ion GC-XA2 }\end{array}$ & $\$ 299$ & $40 \mathrm{~m}$ & $160^{\circ}$ & $74 \times 53 \times 35$ & 135 & $2: 00$ & 720p; 960p; 1080p/30 - 120 & $16 ; 15$ \\
\hline $\begin{array}{l}\text { Sony Action } \\
\text { Cam HDR }\end{array}$ & $\$ 299$ & $5 \mathrm{~m}$ & $170^{\circ}$ & $24 \times 47 \times 82$ & 67 & $2: 30$ & $1080 p ; 720 p / 30-120$ & 13.5; NA \\
\hline $\begin{array}{l}\text { Shimano } \\
\text { CM-1000 }\end{array}$ & $\$ 299$ & $10 \mathrm{~m}$ & $180^{\circ}$ & $71 \times 44 \times 30$ & 86 & $2: 00$ & 360p;720p;1080p/30-240 & 6; NA \\
\hline
\end{tabular}


structures such as fishing gear, substrate, cages, aerial vehicles, trees, or observers themselves.

\section{Picture Quality}

Imagery is predominately determined by the combination of picture resolution, frame rate, and the quality of the lens and image sensor. Most ACs deliver both still imagery, as well as high-definition (HD) video at $720 \mathrm{p}$ and $1,080 \mathrm{p}$ resolution, providing crisp imaging and fine detail (Table 1). Some AC devices can also film in slow motion, with higher frame rates (frames per second [fps]) such as 360p240fps or 720p120fps, providing the ability to slow down video footage to observe subtle, rapid behaviors or events. Many ACs come equipped with complementary metal oxide semiconductor image sensors and high-quality lenses that deliver image resolution ranging between 12 and 16 megapixels, photo-burst capabilities, lowlight sensitivity, and digital stabilization for optimal results in low-light and active environments. However, image quality ranges widely between products based on camera characteristics and price. Wide-angle lenses, also known as "fisheye" lenses, have become standard on ACs and offer up to an 180-degree viewing angle (e.g., Shimano CM-1000, Sakai City, Japan). Wide-angle viewing provides a large field of view and reduces the chance of missing subjects (i.e., study specimens, habitat mapping). Some manufacturers have developed rotating lens systems and multiple lenses on a single camera for capturing footage from different angles (e.g., Oregon Scientific ATC Dual Lens Action Camera, Portland, OR, USA).

\section{APPLICATIONS}

Experimental/exploratory research tools are required to be unobtrusive, time-efficient, and cost-effective (Rezzolla et al. 2014). Similarly, camera systems should not impact the systems or behavior of animals (Koslow et al. 1995). Though historically this might have been an issue (Collins et al. 1991), contemporary ACs provide a noninvasive technique that complements or replaces other sampling methods such as netting, electrofishing, and diver transects (Ellender et al. 2012). For example, Assis et al. (2013) compared remotely captured AC footage (i.e., two ACs mounted side-by-side on a stationary tripod) to SCUBA diver-derived census data. They found that SCUBA surveys frequently produced biased assessments of fish assemblages when conducting underwater visual assessments. In contrast, ACs did not have this effect on fish assemblages and supported the notion that these devices are less intrusive than conventional underwater census techniques. Action camera systems are particularly useful when dealing with species that are sensitive to disturbance as well as for assessing threatened fish populations where other assessment techniques may cause further harm (Weyl et al. 2013).

\section{Types of Application Field Research}

In recent years, the usefulness of AC systems for studying animal behavior in both marine and freshwater environments is becoming recognized. Considerable focus has been placed on studying fish behavior in both marine and freshwater environments using AC devices (Figure 2). For example, Hammar et al. (2013) employed a stereo-video system consisting of multiple $\mathrm{AC}$ units to document fish interactions with a marine hydrokinetic turbine device in three-dimensional video imagery. Domenici et al. (2014) used high-speed, high-definition video footage collected from ACs to present the first analysis of how Atlantic Sailfish Istiophorus albicans use their bill to attack schools of Sardines Sardinella aurita while foraging in the open ocean (Figure 3). Wilson et al. (2014) used handheld ACs to study cooperative and antagonistic interactions between cleaner fish and other members of the fish species assemblage on the Great Barrier Reef. Binder et al. (2015) were able to mount cameras on spawning substrate to document Lake Trout Salvelinus namaycush spawning behavior in Lake Huron-a first for the Laurentian Great Lakes. Researchers have also utilized in situ ACs to record behavior and space-use of juvenile wild fish (Roundhead Galaxiid Galaxias anomalus; Brown Trout Salmo trutta) while foraging; traditional approaches, such as visual observations, would have been inappropriate for this purpose (Vivancos and Closs, in press).

Action cameras have also been used for assessing how fish and other organisms (e.g., prawns, turtles) interact with commercial and recreational fishing gear to inform management (Bacheler et al. 2013; Bayse et al. 2014). For example, Lomeli and Wakefield (2014) used an AC device to evaluate the effectiveness of an artificial lighting system for assisting juvenile Chinook Salmon $O$. tshawytscha escape through a bycatch reduction device (BRD) on a commercial trawling net. Although they conceded that their sample size was rather low, their research with AC devices revealed that the BRD proved to be more effective when the artificial lighting system was operational. Additionally, Cairns et al. (2013) used ACs to make in situ observations of how modification to BRDs could exclude freshwater turtle species from commercial fishing nets while maintaining high capture rates of target fish species (Figure 4). Robbins et al. (2013) used in-line ACs for assessing Sand Tiger Shark Carcharias taurus interactions with recreational fishing gear. In this case, ACs provided information for managers to regulate gear selection and modify angler behavior within the home range of Sand Tiger Sharks to reduce bycatch of this critically endangered species in eastern Australia. Furthermore, Bacheler et al. (2013) used ACs to document the saturation time of chevron traps - a common tool used for assessing community assemblages and abundances of marine fish. They monitored the entry and exit of Black Sea Bass Centropristis striata through a chevron trap while it was actively fishing to determine the soak time saturation. From their research with AC units, they were able to address concerns regarding unrealistic population inferences using catch per unit effort due to the saturation effect of trap nets.

Another common application of ACs is studies that assess fish abundance and community structure in marine (Clarke et al. 2012; Cullen 2013; Harasti et al. 2014) and freshwater (Weyl et al. 2013) ecosystems. For example, Letessier et al. (2013) presented research using ACs for assessing the abundance and size estimates of fish that passed within the field of view of the camera unit. They used ACs to record pelagic fish assemblages in marine protected areas where other assessment methods would be invasive for sensitive/protected aquatic habitat. Clarke et al. (2012) used ACs to monitor the abundance of sharks at remote coral reefs in the Indian Ocean. For their research, they utilized a baited mesh bag in front of the AC, also known as a mini-baited remote underwater video (BRUV), to attract sharks. Harasti et al. (2014) also used mini-BRUVs to document distribution and abundance of juvenile Black Cod Epinephelus daemelii in rock pools and intertidal habitats. They determined that mini-BRUVs were a successful method to document 


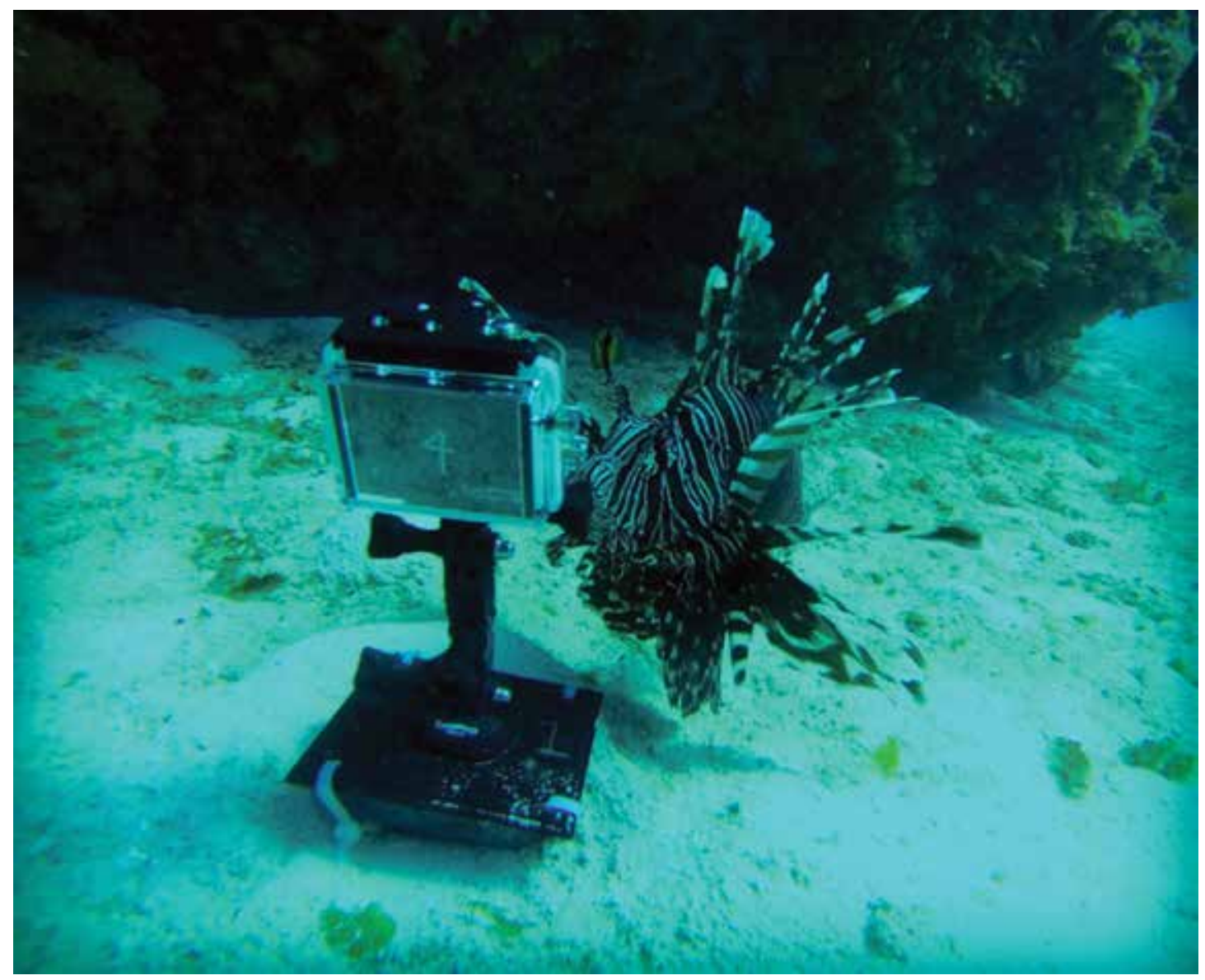

Figure 2. Zebra Lionfish Dendrochirus zebra behavior documented within the field of view of an action camera situated in reef habitat of the Bahamas. Photo credit: Tye Lindinger.

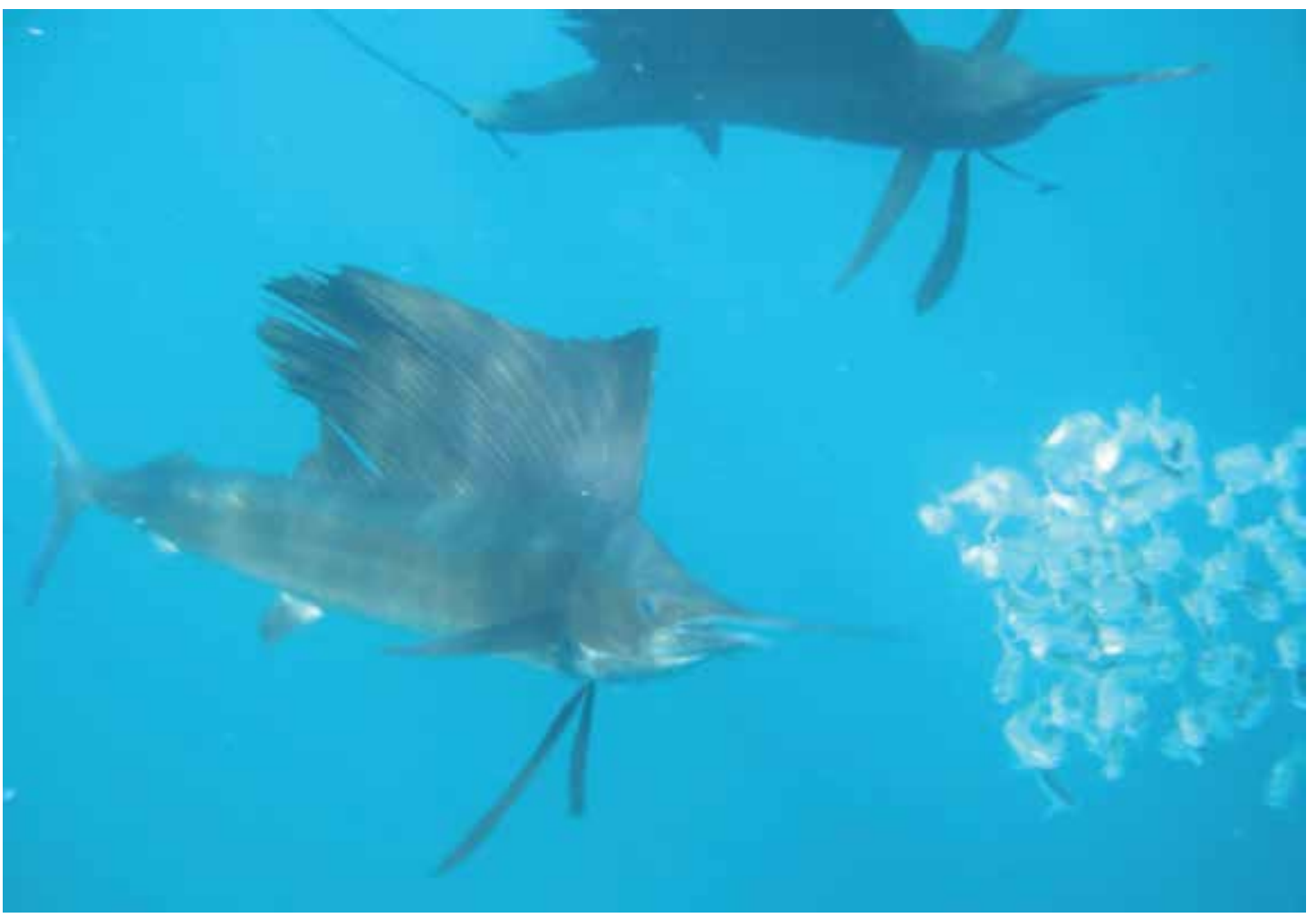

Figure 3. Action camera footage that captured a feeding event of an Atlantic Sailfish chasing a school of sardines. Photo credit: Alexander Wilson. 


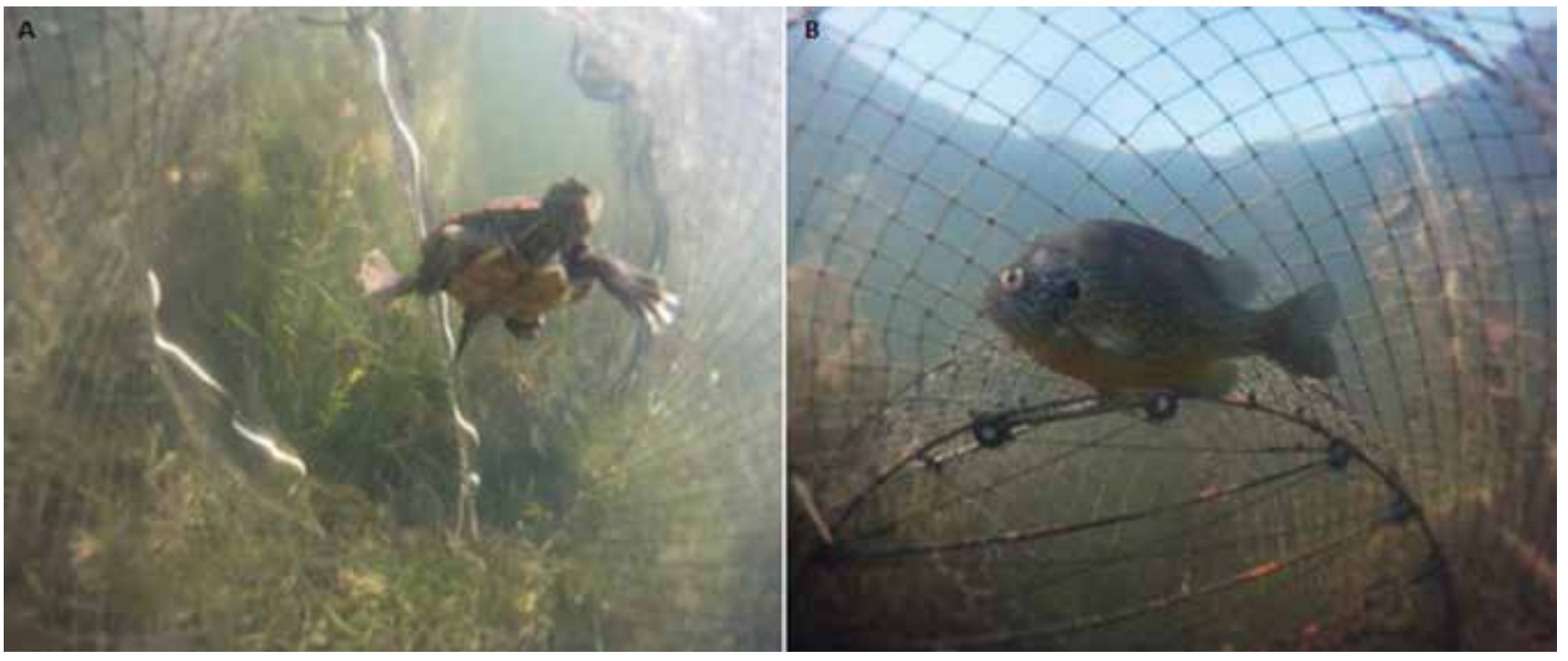

Figure 4. (A) Freshwater turtle and (B) sunfish documented in a commercial fishing net by an action camera device. Photo credit: Nick Cairns.

E. daemelii during early stages and were more efficient in determining presence/absence than conventional visual or trap surveys.

Habitat and bathymetry mapping has also been performed with ACs. High-definition picture quality and wide-angle lenses have improved the ability to produce detailed habitat mapping of aquatic environments. For example, Schmidt and Rzhanov (2012) presented a preliminary study using AC devices to map the topography of the seafloor at fine-scale resolution that was comparable to sonar devices traditionally used for ocean bathymetry research. They used a GoPro AC

\section{ACs can be used to monitor animal interactions, document disease and mortality, and operate successfully in almost any situ- ation in which visual observations or cabled video might have previously been useful.}

because this manufacturer provides a specialized stereo-video kit that includes a waterproof housing and cables to synchronize video footage for two tandem mounted ACs to produce threedimensional imaging. The stereo-imaging system for the GoPro cameras provided a cost-effective alternative compared to expensive bathymetry sonar devices that are commonly used (Schmidt and Rzhanov 2012). Furthermore, researchers have compared a number of AC systems for mapping and monitoring benthic coral reef habitat (Gintert et al. 2012). The AC unit (i.e., GoPro HERO) ranked third in their results because it provided clear benthic imagery at a tenth of the price of other top-ranking camera units. As such, ACs are a favorable option for contemporary coral reef habitat monitoring/mapping projects (Gintert et al. 2012).

Aerial surveys of aquatic habitats and watersheds are now possible through the use of unmanned aerial vehicles (UAVs) mounted with ACs. Relatively small, portable remote-controlled aircraft are able to easily lift ACs, capturing aerial HD video and still images with accuracy and precision (Figure 5).In addition, some UAVs are small enough to be used in locations where conventional aircraft are impractical. Both fixed-wing and multirotor aircraft mounted with $\mathrm{AC}$ devices add a new dimension to fisheries and aquatic research. However, this technology is not without obstacles such as specialized training that is required and environmental variables (i.e., rain, wind, and glare from sunlight), which can limit $\mathrm{AC}$ and UAV performance as well as the country-specific regulations for the operation of UAVs.

$$
\text { Animal-Borne }
$$

Animal-borne research, based on devices being directly affixed to aquatic animals, has become increasingly possible as a result of ACs being ever smaller and lighter. Animal-borne research provides the perspective of an animal for documenting the natural behavior and interactions that otherwise may not be possible by other observation approaches (Thomson and Heithaus 2014). Although not truly an AC, the National Geographic Crittercam has been used for a variety of animalborne projects, such as Calambokidis et al. (2002) documenting the behavior of blue whales Balaenoptera musculus, Parrish and Littnan (2007) recording the foraging behavior of the Hawaiian monk seal Monachus schauinslandi, and Heithaus et al. (2001) monitoring the habitat use of Tiger Sharks Galeocerdo cuvier. However, devices like the Crittercam are relatively large and expensive, limiting their role in aquatic research applications.

Despite the affordability, small size, and low cost of AC devices, animal-borne studies have not yet been widely implemented at present. Only recently have researchers begun to realize the potential for this form of research with ACs. However, there have been a small number of studies successfully mounting AC units to aquatic animals. For example, researchers have recently mounted an AC to the dorsal surface of a Common Carp Cyprinus carpio to better understand how this species might migrate through a fish passage facility (BFWR 2014). Additionally, Thomson and Heithaus (2014) were able to mount ACs to the carapace of green turtles Chelonia mydas to investigate the characteristics of natural swimming behavior, habitat usage, and interactions between conspecifics and other species. As AC systems are designed to make camera retrieval easier and are further miniaturized, we anticipate greater use of ACs for animal-borne videography. Nonetheless, it is important 


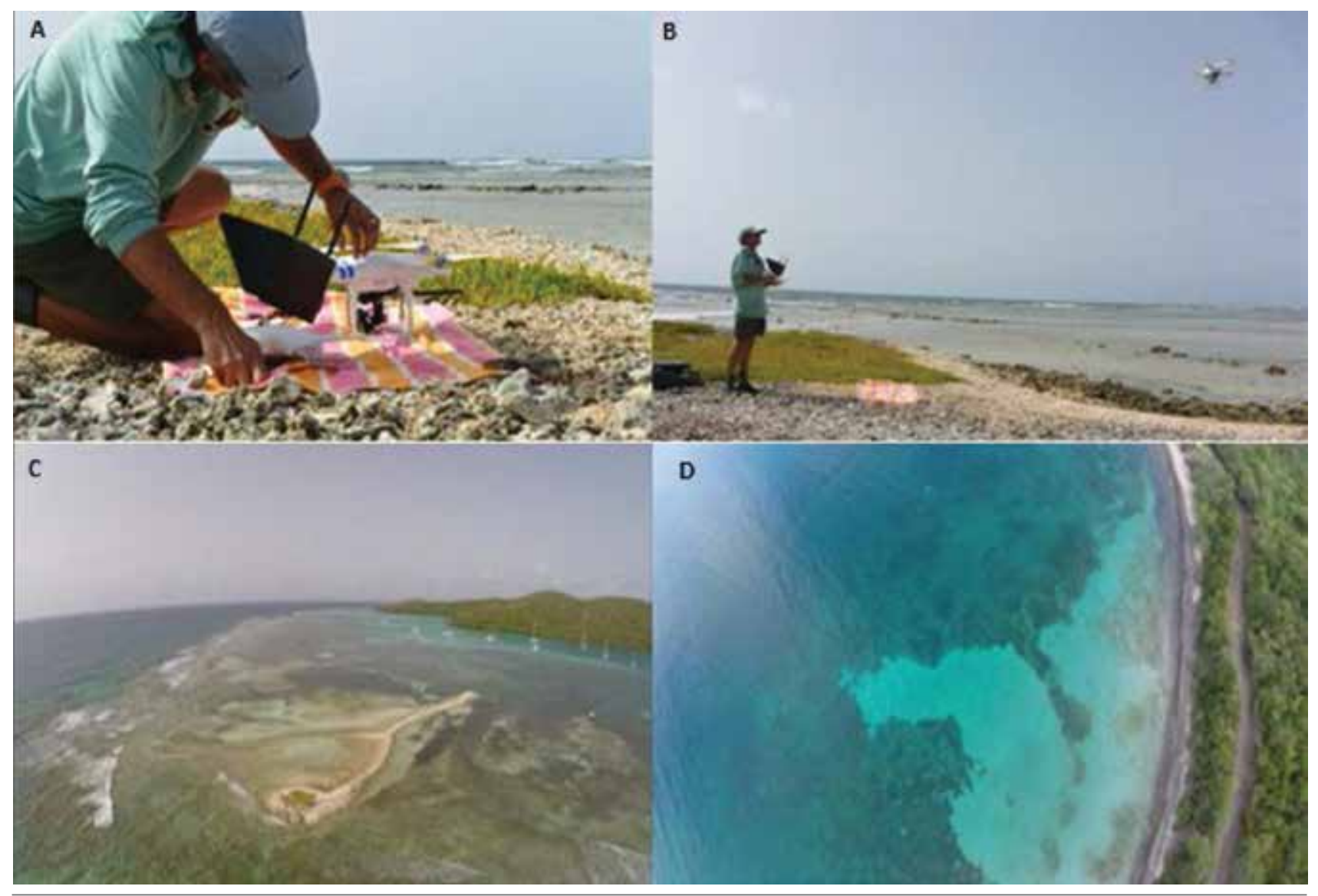

Figure 5. Multirotor UAV being used for habitat surveys in shallow tropical seas. (A) Mounting action camera to UAV. Photo credit: Tyler Gagne. (B) Remote control operation of UAV. Photo credit: Tyler Gagne. (C) UAV collecting high-definition imagery of reef habitat with action camera. Photo credit: Andy Danylchuk. (D) Large-scale habitat mapping from a UAV. Photo credit: Andy Danylchuk.

to ensure that such applications do not exceed tag burdens for aquatic animals and are streamlined to minimize drag.

$$
\text { Laboratory }
$$

Action camera technologies have also shown to be useful in studying animals in a captive or laboratory setting. Johansen et al. (2014) used ACs to determine how warming water temperatures would affect fish movement and activity response on coral reefs. Rivera-Posada et al. (2013) experimented with administering organically derived substances as a biocontrol technique for managing invasive crown-of-thorns starfish Acanthaster planci that are causing worldwide decline of coral reefs. Action cameras were used here to monitor animal interactions, assess unintended side effects on other coral reef organisms, and document signs of disease and mortality in the study animals. Action cameras have also been used to measure the response of Zebrafish Danio rerioare, a fish species commonly used for biomedical research (Linney et al. 2004; Cachat et al. 2010; Gilbert et al. 2014), to the addition of a psychoactive compound (ethanol) into their environment (Ladu et al. 2014). The researchers used an overhead AC to gather swim trajectory information to assess variation in social behavior between treatment and control groups. In another example, Underwood et al. (2014) used ACs to document swimming performance (critical swimming velocity $\left[U_{\text {crit }}\right]$ ) of six common fishes in the laboratory to determine whether they could be used as proxies for similar species that may be rare or threatened. These examples showcase how ACs can be used to monitor animal interactions, document disease and mortality, and operate successfully in almost any situation in which visual observations or cabled video might have previously been useful. Compared to traditional cameras, ACs are beneficial in the laboratory for when the researcher requires a wide field of view, high-quality imagery, and flexible mounting options to capture data from unique aspects.

$$
\text { Education and Outreach }
$$

Action cameras are an engaging tool for educational and outreach purposes. They are a unique videography tool for illustrating the researcher's fieldwork experiences as well as animal behavior in a natural environment. Research groups are using AC footage on webpages as well as social networking and video-sharing websites (i.e., YouTube, Facebook, and Twitter) to exemplify and publicize research projects and attract prospective students for research opportunities. For example, the Great Lakes Fishery Commission (GLFC) has provided a number of open-access videos on their website for educational and outreach purposes. The GLFC video database provides videographic illustrations of fish behavior, fisheries, invasive species, and fish habitat taken from underwater ACs (GLFC 2014). Another example is the St. Lawrence River Institute of Environmental Sciences, which hosts an advertisement video on their website highlighting their eel research program that includes underwater footage captured with AC devices (SLRI 2014). Action camera footage is also widely used by professors and scholars for presentations to classes, workshops, meetings, or other professional settings to engage audiences. 


\section{Challenges and Limitations}

\section{Deployment Considerations}

There are important deployment considerations that are recommended before proceeding with the application of ACs for a research project. Scientists need to explore the numerous products that are available for balancing cost with the level of data resolution needed for the research application. In addition, researchers need to consider a number of experimental design factors prior to deploying ACs for research, including the following: How should the AC be attached for optimal results? Should it be placed above the water, placed in situ, or animalborne? Will the cameras require an artificial lighting system? How many cameras are required? Furthermore, researchers need to carefully consider how the data should be collected to (1) reduce sampling biases (i.e., pseudoreplication and underrepresentation of species or habitat types), (2) reduce zeroinflated data, and (3) identify and remove artifacts from the data set, as well as how to manage and analyze large imagery data sets.

\section{Data and Analysis}

Video data can be difficult and time consuming to retrieve, edit, manage, and analyze. Although Wi-Fi connectivity is becoming a standard in the latest ACs, there are still limitations for ACs to provide real-time data (Robbins et al. 2013). For example, wireless signals cannot be transmitted underwater and can also quickly drain batteries, greatly reducing observation duration. Furthermore, in instances where direct signals cannot be obtained, there is a risk of wasted effort due to various factors such as water damage, dead batteries, unfocused/blurry image, ambient lighting, or barriers blocking the field of view.

Although software packages and statistical tools have been developed to deal with challenging and nonorthogonal data sets (e.g., Generalized Additive Models, Generalized Linear MixedModels, zero-inflated models), exploring the video data can be a time-consuming process (Moll et al. 2007). When time is limited for analysis, researchers may streamline the process by sampling subsections of the imagery and then extrapolating. This may lead to skipping over important findings (i.e., rare events, species, or habitat types) and making overgeneralizations by missing nuances in the imagery data. Using ACs can also limit the researcher's ability to identify or detect points of interest (i.e., distinctions in habitat characteristics or small fish) if they are recorded far from where the camera is situated. Additionally, there is the issue of pseudoreplication caused by counting the same animal repeatedly if there is no way to uniquely identify them as they continuously pass by the camera's field of view. Therefore, sampling design is a fundamental component that researchers need to consider carefully prior to deploying AC devices to minimize sample error. An important feature available with some ACs is the option of flexible programming wherein one can set a delayed recording time as well as setting recording intervals to spread out sampling effort, extend deployment time, and reducing serial autocorrelation. Researchers should therefore carefully evaluate sampling options available with different camera models and accessories relative to their sampling design needs.

\section{Animal-Borne Research}

As with all biologging and biotelemetry devices, there is concern regarding how the device may affect the natural behavior of study animals. Before implementing an animalborne study, researchers should consider methods to minimize the effects that $\mathrm{AC}$ devices and mounting systems have on the natural behavior of the study specimens (e.g., programming time delayed recordings from tagged animals, neutrally buoyant cameras, using ACs that minimize drag). Furthermore, attaching and retrieving ACs from aquatic organisms can be a difficult procedure that requires custom mounting systems. Similar to traditional biologging devices, AC units need to be retrieved from the animal to collect the data. Retrieving an AC unit from aquatic animals can be challenging without using devices to automate retrieval (i.e., pop-up devices) because the tagged animal would need to be located and recaptured to download footage. Furthermore, AC units are still limited by the depth rating of underwater housing systems provided by manufacturers. Unless custom housings are used, depth restricts the application on aquatic animals that may exceed the maximum depth rating of the AC device.

\section{Environmental Constraints}

There are also a variety of challenges for deploying ACs in dynamic environments. Researchers are often limited by turbid water, as well as deep water, and nocturnal recordings where ambient light is not sufficient, and artificial lighting systems may not be suitable (Schmidt and Rzhanov 2012). Fish abundance and community diversity studies that are completed without using a lighting apparatus are generally restricted to the diurnal period and shallow and clear water environments. As a result, community assessments from video footage taken only during the daytime may produce unrepresentative findings, because nocturnally active species are likely to be overlooked (Hammar et al. 2013; Weyl et al. 2013). Furthermore, there are several other factors to consider, such as color distortion, depth limitations of underwater housings, biofouling, corrosion from saltwater, theft, vandalism, image instability, and cold environments that reduce battery life.

\section{CONCLUSION}

\section{Continued Technological Improvements}

In recent years, technological innovations have resulted in a number of improvements to $\mathrm{AC}$ equipment that make them more applicable for aquatic research purposes. First, if consumers demonstrate a demand for enhanced waterproofing ratings, manufacturers will continue developing camera and housing systems that can be used at greater depths. For ACs deployed above water, Wi-Fi communication will likely become commonplace, providing researchers with the ability to monitor camera functionality and gather data in real time. Action cameras are also becoming integrated with geographic positioning systems (e.g., Argos satellite system), which can be useful for tracking animals that breach the surface long enough to record their geographic position. Innovations with rechargeable lithium-ion batteries will likely continue and allow researchers to deploy ACs for longer duration in cold environments and remote locations. Furthermore, based on the rate of rapid technological advances in the last decade with $\mathrm{AC}$ units, we expect the dimensions of ACs to become smaller and lighter and housing systems to be rated to greater depth. For example, the GoPro HERO $3+$ is $20 \%$ smaller and lighter than the previous HERO and HERO 2 models (GoPro 2014). Where previous AC models were restricted, these technological advances will make animal-borne research possible for smaller animals and species that utilize greater depths. Furthermore, integrating sensors into cameras may be an avenue for manufacturers to explore as scientific demand increases for AC devices. Such sensors have already been integrated with the 
National Geographic Crittercam and have been coupled with ACs on green turtles (Thomson and Heithaus 2014). Integrating accelerometer, pressure, or temperature sensors in AC devices would be beneficial by providing further insight into animal behavior by relating imagery data with movement responses or environmental data for animal-borne research.

\section{Outlook}

Action camera technology is advancing and will be increasingly used for creative applications in fisheries and aquatic research. Action cameras may be beneficial in future research applications such as documenting rare events (e.g. Wilson and Krause 2013), implementing animal-borne studies on a diversity of aquatic animals, monitoring fish movements through fishways and corridors, monitoring interactions with recreational and commercial fishing gear, quantifying biomechanics and energetics, validating ecological models, and many other creative applications. However, research ideas for using AC units in research may potentially outpace technological advancements, causing research to be postponed until AC products are further improved (e.g., made smaller, longer battery life, integrated sensors). Nevertheless, as the use of ACs becomes commonplace for research, demand may increase and continue to encourage manufacturers to develop specialized mounting systems and improve the technology specifically for the research-based applications. However, aftermarket housings and mountings systems will be required to some extent by researchers because the development of ACs is largely driven by recreation and sports market, rather than science.

The use of AC technology is only as important as the research questions being asked. Researchers need to combine the right tool for the right purpose to elicit quantitatively important findings that are noteworthy to report in the literature. Techniques and tools are continually being developed for effective analyses of videographic data for scientists working with large complicated data sets. Though limitations and challenges exist, scientists are using AC devices for innovative applications in aquatic and fisheries research whose applications are only limited by the imagination of those using them.

\section{ACKNOWLEDGMENTS}

We thank several individuals for providing images and several referees for providing insightful input on the article.

\section{FUNDING}

S. J. Cooke is supported by the Natural Sciences and Engineering Research Council of Canada and the Canada Research Chairs Program. A. J. Danylchuk is supported by the National Institute of Food and Agriculture, U.S. Department of Agriculture, and Massachusetts Agricultural Experiment Station and Department of Environmental Conservation.

\section{REFERENCES}

Ang, K. P., and R. J. Petrell. 1997. Control of feed dispensation in sea cages using underwater video monitoring: effects on growth and food conversion. Aquacultural Engineering 16:45-62.

Assis, J., B. Claro, A. Ramos, J. Boavida, and E. A. Serrão. 2013. Performing fish counts with a wide-angle camera, a promising approach reducing divers' limitations. Journal of Experimental Marine Biology and Ecology 445:93-98.

Bacheler, N. M., Z. H. Schobernd, D. J. Berrane, C. M. Schobernd, W. A. Mitchell, and N. R. Geraldi. 2013. When a trap is not a trap: converging entry and exit rates and their effect on trap saturation of Black Sea Bass (Centropristis striata). Marine Science 70:873-882.
Barnes, H. 1952. Under-water television and marine biology. Nature 169:477-479.

Bayse, S. M., P. He, M. V. Pol, and D. M. Chosid. 2014. Quantitative analysis of the behavior of longfin inshore squid (Doryteuthis pealeii) in reaction to a species separation grid of an otter trawl. Fisheries Research 152:55-61.

Beddow, T. A., L. G. Ross, and J. A. Marchant. 1996. Predicting salmon biomass remotely using a digital stereo-imaging technique. Aquaculture 146:189-203.

Bellis, M. 2004. History of the digital camera. Available: inventors. about.com/library/inventors/bldigitalcamera.htm. (July 2014).

Binder, T. R., H. T. Thompson, A. M. Muir, S. C. Riley, J. E. Marsden, C. R. Bronte, and C. C. Krueger. 2015. New insight into the spawning behavior of Lake Trout, Salvelinus namaycush, from a recovering population in the Laurentian Great Lakes. Environmental Biology of Fishes. 98:173-181.

BFWR (Biotactic Fisheries and Wildlife Research). 2014. Carp Cam. Available: biotactic.com/bravo/archive/CarpCam/carpcam.htm. (July 2014).

Booth, D. J., and G. A. Beretta. 2002. Changes in a fish assemblage after a coral bleaching event. Marine Ecology Progress Series 245:205-212.

Brawn, V. M. 1960. Underwater television observations of the swimming speed and behaviour of captive herring. Journal of the Fisheries Board of Canada 17:689-698.

Cachat, J., P. Canavello, M. Elegante, B. Bartels, P. Hart, C. Bergner, and A. V. Kalueff. 2010. Modeling withdrawal syndrome in Zebrafish. Behavioural Brain Research 208:371-376.

Cairns, N. A., L. J. Stoot, G. Blouin-Demers, and S. J. Cooke. 2013. Refinement of bycatch reduction devices to exclude freshwater turtles from commercial fishing nets. Endangered Species Research 22:251-261

Calambokidis, J., J. Francis, G. Marshall, D. Croll, M. McDonald, and T. Williams. 2002. Underwater behavior of blue whales using a suction-cup attached Crittercam. Cascadia Research Collective, Olympia, Washington.

Carleton, J. H., and T. J. Done. 1995. Quantitative video sampling of coral reef benthos: large-scale application. Coral Reefs 14:35-46.

Clarke, C., J. Lea, and R. Ormond. 2012. Comparative abundance of reef sharks in the western Indian Ocean. Proceedings of the 12th International Coral Reef Symposium, Cairns, Australia.

Collins, N. C., S. G. Hinch, and K. A. Baia. 1991. Non-intrusive time lapse video monitoring of shallow aquatic environments. Fisheries and Oceans Canada, Canadian Technical Report of Fisheries and Aquatic Sciences 1821, Burlington, Ontario.

Cooke, S. J., and C. M. Bunt. 2004. Construction of a junction box for use with an inexpensive, commercially available underwater video camera suitable for aquatic research. North American Journal of Fisheries Management 24:253-257.

Cooke, S. J., and J. F. Schreer. 2002. Determination of fish community composition in the untempered regions of a thermal effluent canal-the efficacy of a fixed underwater videography system. Environmental Monitoring and Assessment 73:109-129.

Costa, C., A. Loy, S. Cataudella, D. Davis, and M. Scardi. 2006. Extracting fish size using dual underwater cameras. Aquacultural Engineering 35:218-227.

Cullen, D. W. 2013. Comparing baited and unbaited video to assess the abundance and behavior of Black Sea Bass. 143rd Annual Meeting of the American Fisheries Society, Little Rock, Arkansas.

De Leo, F. C., C. R. Smith, A. A. Rowden, D. A. Bowden, and M. R. Clark. 2010. Submarine canyons: hotspots of benthic biomass and productivity in the deep sea. Proceedings of the Royal Society B: Biological Sciences 277:2783-2792.

Domenici, P., A. D. M., Wilson, R. H. J. M. Kurvers, S. Marras, J. E. Herbert-Read, J. F. Steffensen, and J. Krause. 2014. How sailfish use their bills to capture schooling prey. Proceedings of the Royal Society B: Biological Sciences 281:20140444.

Ellender, B. R., A. Becker, O. L. Weyl, and E. R. Swartz. 2012. Underwater video analysis as a non-destructive alternative to electrofishing for sampling imperilled headwater stream fishes. Aquatic Conservation: Marine and Freshwater Ecosystems 22:58-65.

Foster, M., R. Petrell, M. R. Ito, and R. Ward. 1995. Detection and counting of uneaten food pellets in a sea cage using image analysis. Aquacultural Engineering 14:251-269.

Gilbert, M. J., T. C. Zerulla, T. C., and K. B. Tierney. 2014. Zebrafish (Danio rerio) as a model for the study of aging and exercise: physical ability and trainability decrease with age. Experimental Gerontology 50:106-113. 
Gintert, B., A. C. R. Gleason, K. Cantwell, N. Gracias, M. Gonzalez, and R. P. Reid. 2012. Third-generation underwater landscape mosaics for coral reef mapping and monitoring. Proceedings of the 12th International Coral Reef Symposium, Cairns, Australia.

GLFC (Great Lakes Fishery Commission). 2014. Video gallery. Available: glfc.org/multimedia/videos.php\#. (July 2014).

GoPro. 2014. HERO 3+ black edition. Available: gopro.com/cameras/ hd-hero3-black-edition. (July 2014).

Hammar, L., S. Andersson, L. Eggertsen, J. Haglund, M. Gullström, J. Ehnberg, and S. Molander. 2013. Hydrokinetic turbine effects on fish swimming behaviour. PloS One 8:e84141.

Harasti, D., C. Gallen, H. Malcolm, P. Tegart, and B. Hughes. 2014 Where are the little ones: distribution and abundance of the threatened Serranid Epinephelus daemelii (Günther, 1876) in intertidal habitats in New South Wales, Australia. Journal of Applied Ichthyology 30:1007-1015.

Harvey, E., D. Fletcher, and M. Shortis. 2002. Estimation of reef fish length by divers and by stereo-video: a first comparison of the accuracy and precision in the field on living fish under operational conditions. Fisheries Research 57:255-265.

He, P. 2003. Swimming behaviour of Winter Flounder (Pleuronectes americanus) on natural fishing grounds as observed by an underwater video camera. Fisheries Research 60:507-514.

Heithaus, M. R., L. M. Dill, G. Marshall, and B. M. Buhleier. 2002. Habitat use and foraging behavior of Tiger Sharks (Galeocerdo cuvier) in a seagrass ecosystem. Marine Biology 140:237-248.

Heithaus, M. R., G. J. Marshall, B. M. Buhleier, and L. M. Dill. 2001. Employing Crittercam to study habitat use and behavior of large sharks. Marine Ecology Progress Series 20:307-310.

Hinch, S. G., and P. S. Rand. 2000. Optimal swimming speeds and forward-assisted propulsion: energy-conserving behaviours of upriver-migrating adult salmon. Canadian Journal of Fisheries and Aquatic Sciences 57:2470-2478.

Hughes, N. F., J. W. Hayes, K. A. Shearer, and R. G. Young. 2003. Testing a model of drift-feeding using three-dimensional videography of wild Brown Trout, Salmo trutta, in a New Zealand river. Canadian Journal of Fisheries and Aquatic Sciences 60:14621476.

Johansen, J. L., V. Messmer, D. J. Coker, A. S. Hoey, and M. S. Pratchett. 2014. Increasing ocean temperatures reduce activity patterns of a large commercially important coral reef fish. Global Change Biology 20:1067-1074.

Koslow, J. A., R. Kloser, and C. A. Stanley. 1995. Avoidance of a camera system by a deepwater fish, the Orange Roughy (Hoplostethus atlanticus). Deep Sea Research Part I: Oceanographic Research Papers 42:233-244.

Kumpf, H. E., and J. M. Lowenstein. 1962. Undersea observation station. Sea Frontiers 8:198-206.

Ladu, F., S. Butail, S. Macrí, and M. Porfiri. 2014. Sociality modulates the effects of ethanol in Zebrafish. Alcoholism: Clinical and Experimental Research 38:2096-2104.

Letessier, T. B., J. J. Meeuwig, M. Gollock, L. Groves, P. J. Bouchet, L. Chapuis, and H. J. Koldewey. 2013. Assessing pelagic fish populations: the application of demersal video techniques to the midwater environment. Methods in Oceanography 8:41-55.

Linney, E., L. Upchurch, and S. Donerly. 2004. Zebrafish as a neurotoxicological model. Neurotoxicology and Teratology 26:709718.

Livingstone, R. 1962. Underwater television observations of Haddock (Melanogrammus aeglefinus [Linnaeus]) in the cod-end. ICES Journal of Marine Science 27:43-48.

Lomeli, M. J. M., and W. W. Wakefield. 2014. Examining the potential use of artificial illumination to enhance Chinook Salmon escapement out a bycatch reduction device in a Pacific Hake midwater trawl. National Marine Fisheries Service, Northwest Fisheries Science Center Report, Seattle, WA.
Michel, A. P. M., K. L. Croff, K. W. McLetchie, and J. D. Irish. 2002. A remote monitoring system for open ocean aquaculture. Proceedings of the 2002 Oceans MTS/IEEE symposium, Biloxi, Mississippi.

Moll, R. J., J. J. Millspaugh, J. Beringer, J. Sartwell, and Z. He. 2007. A new "view" of ecology and conservation through animal-borne video systems. Trends in Ecology and Evolution 22:660-668.

Mueller, R. P., R. S. Brown, H. Hop, and L. Moulton. 2006. Video and acoustic camera techniques for studying fish under ice: a review and comparison. Reviews in Fish Biology and Fisheries 16:213226.

Myrberg, A. A., Jr., A. Banner, and J. D. Richard. 1969. Shark attraction using a video-acoustic system. Marine Biology 2:264-276.

Parrish, F. A., and C. L. Littnan. 2007. Changing perspectives in Hawaiian monk seal research using animal-borne imaging. Marine Technology Society Journal 41:30-34.

Rezzolla, D., G. Boldrocchi, and T. Storai. 2014. Evaluation of a lowcost, non-invasive survey technique to assess the relative abundance, diversity and behaviour of sharks on Sudanese reefs (Southern Red Sea). Journal of the Marine Biological Association of the United Kingdom 94:599-606.

Richard, J. D. 1968. Fish attraction with pulsed low-frequency sound Journal of the Fisheries Board of Canada 25:1441-1452.

Rivera-Posada, J., C. F. Caballes, and M. S. Pratchett. 2013. Lethal doses of oxbile, peptones and thiosulfate-citrate-bile-sucrose agar (TCBS) for Acanthaster planci; exploring alternative population control options. Marine Pollution Bulletin 75:133-139.

Robbins, W. D., V. M. Peddemors, M. K. Broadhurst, and C. A. Gray. 2013. Hooked on fishing? Recreational angling interactions with the critically endangered grey nurse shark Carcharias taurus in eastern Australia. Endangered Species Research 21:161-170.

Schmidt, V. E., and Y. Rzhanov. 2012. Measurement of micro-bathymetry with a GOPRO underwater stereo camera pair. Proceedings of the 2012 Oceans MTS/IEEE Symposia, Hampton Roads, Virginia.

Steinberg, J. C., W. C. Cummings, B. D. Brahy, and J. Y. Macbain (Spires). 1965. Further bio-acoustic studies off the west coast of North Bimini, Bahamas. Bulletin of Marine Science 15:942-963.

Stevenson, R. A., and A. A. Myrberg, Jr. 1966. Behavior of the bicolor Damselfish, Eupomacentrus partitus, in the field and in the aquarium. American Zoologist 6:516.

St. Lawrence River Institute of Environmental Sciences. 2014. The Eel Team. Available: riverinstitute.ca. (July 2014).

Thomson, J. A., and M. R. Heithaus. 2014. Animal-borne video reveals seasonal activity patterns of green sea turtles and the importance of accounting for capture stress in short-term biologging. Journal of Experimental Marine Biology and Ecology 450:15-20.

Underwood, Z. E., C. A. Myrick, and R. I. Compton. 2014. Comparative swimming performance of five Catostomus species and roundtail chub. North American Journal of Fisheries Management 34:753-763.

Vivancos, A., and G. P. Closs. In Press. Quantification and comparison of individual space-use strategies in foraging drift-feeding fish using fine-scale, multi-dimensional movement analysis. Canadian Journal of Fisheries and Aquatic Sciences.

Weyl, O., B. Ellender, D. Woodford, and M. Jordaan. 2013. Fish distributions in the Rondegat River, cape floristic region, South Africa, and the immediate impact of rotenone treatment in an invaded reach. African Journal of Aquatic Science 38:201-209.

Wilson, A. D. M., and J. Krause. 2013. Repeated non-agonistic interactions between a bottlenose dolphin (Tursiops truncatus) and sperm whales (Physeter macrocephalus) in Azorean waters. Aquatic Mammals 39:89-96.

Wilson, A. D., J. Krause, J. E. Herbert-Read, and A. J. Ward. 2014. The personality behind cheating: behavioural types and the feeding ecology of cleaner fish. Ethology 120:1-9. AFS 